\title{
Effects of Zinc Addition on the Performance of Aluminium as Sacrificial Anode in Seawater
}

\author{
Muazu, A. ${ }^{1}$ and Yaro, S. A. ${ }^{2}$ \\ ${ }^{1}$ Department of Mechanical Engineering, Bayero University Kano, Nigeria \\ ${ }^{2}$ Department of Metallurgical and Materials Engineering, Ahmadu Bello University, \\ Zaria, Nigeria \\ ${ }^{1}$ Muazumani2004@yahoo.com; 2yaroaliyu@yahoo.com
}

\begin{abstract}
In this work, the effect of zinc addition on the performance of aluminium-based sacrificial anode in seawater was investigated. The parameters used in assessing the performance of the cast anodes are anodic efficiency, protection efficiency and polarized potential. The percentages of $\mathrm{Zn}$ in the anodes were varied from 1 to $8 \% \mathrm{Zn}$. The alloys produced were tested as sacrificial anode for the protection of mild steel in seawater at room temperature. Current efficiency as high as $86.69 \%$ was achieved at $6 \% \mathrm{Zn}$ in the alloys. The polarized potential obtained for the couples(steel/Al based alloys) are as given in the pourbaix diagrams with the steel lying within the immunity region/cathodic region ( $5-0.5 \mathrm{VSHE}$ ) and the sacrificial anodes within the anodic region. The protection offered by the sacrificial anodes to the steel after the 7th and 8th week were measured. Protection efficiency values as high as $99.26 \%$ and $99.13 \%$ were achieved after the 7th and 8th with Al-6\%Zn. The microstructure showed the intermetallic structures of $\beta$-phase which breakdown the alumina passive film and thus enhancing the anode efficiency.
\end{abstract}

Keywords: Sacrificial anode, anode efficiency, protection efficiency,polarized potential, and anode mass requirement. 


\section{INTRODUCTION}

Cathodic protection by sacrificial anode has gained general acceptance as a means of preventing and protecting metals from corrosion. This is because it has the advantages of being simple to install, independent of a source of external electric power, suitable for localized protection and less liable to cause interaction on neighbouring structures ${ }^{1}$. This is achieved by changing the electrode potential of the metallic structure so that it lies in the immunity region, within this region, the metal is in the stable form of the element and corrosion reactions are therefore impossible ${ }^{4}$. Cathodic protection by sacrificial anode is used to protect engineering structures from corrosion, such as pipelines, underground storage tanks, locks and ship hulls. It is a method of preventing corrosion by minimizing the difference in potential between anode and cathode. This is achieved by supplying a current to the structure to be protected from some outside source, when enough current is applied, the whole structure will be at one potential; thus, anode and cathode sites will not exist ${ }^{5}$. In another words, cathodic protection prevents corrosion by converting all the anodic (active) sites on the metal surface to cathodic (passive) sites by supplying electrical current (free electrons) from an alternate source ${ }^{1}$.

Iron and steel are the most versatile, least expensive and most widely used of the engineering materials. They are unequalled in the range of mechanical and physical properties with which they are endowed by alloying and heat-treatment. Their main disadvantage is that iron and steel have poor resistance to corrosion in relative and mild service environments ${ }^{2}$. But if the potential of iron and steel is made sufficiently negative below $-0.5 \mathrm{~V}$ standard hydrogen electrode (SHE) in neutral or acidic environments, iron and steel will corrode much less. In this region(immunity region), the metal is considered to be totally immuned from corrosion ${ }^{3}$.

Aluminium alloys are normally used in protecting steel structures in seawater because of their better current conductivity and supply largest number of electrons for protection per unit mass. The problem with pure aluminium is that it passivates easily by forming an oxide film that practically prevents contact between the metal and the environment ${ }^{5}$. This necessitated the present research, which is aimed at looking at the possibility of alloying aluminium with zinc in order to enhance its performance as a sacrificial anode for the protection of mild steel in seawater.

Aluminium alloys are the most preferred metals to be used as sacrificial anode in seawater compared to magnesium and zinc, this is because aluminium alloys have large electrochemical equivalent, low density, not wastefully consumed and better current output ${ }^{1,6}$. Pure aluminium is not used as an anode material on account that it easily forms a passive layer of $\gamma-\mathrm{Al}_{2} \mathrm{O}_{3}$ on its surface $^{7,8}$. For used as galvanic anodes, aluminium alloys are employed that contain activating alloying elements that hinder or prevent the formation of surface films. The continuity of the film is affected by the microstructure of the metal, and by the presence and volume fraction of 
second-phase particles. The alloying elements that hinder or prevent the formation of surface film on aluminium are $\mathrm{Zn}, \mathrm{Mg}, \mathrm{Ga}$, In, $\mathrm{Sn}, \mathrm{Bi}$ and $\mathrm{Ti}^{9}$.

\section{MATERIALS}

The high purity aluminium used in this research were obtained from Northern Cable Company (NOCACO) Kaduna, zinc, natural seawater from Lagos, moulding box, permanent mould pipes, distilled water, acetone, ethanol, and etchant.

\section{METHODS}

The Al-Zn alloys used in this study were produced using permanent mould casting. The aluminium obtain was remelted in a muffle furnace. After melting of the pure aluminium, proportionate amounts of $\mathrm{Zn}$ was added to produce alloys of composition $1-8 \% \mathrm{Zn}$ in $\mathrm{Al}-\mathrm{Zn}$ alloys.Preheated permanent moulds with diameter $19 \mathrm{~mm}$ and length $400 \mathrm{~mm}$ length were used to produce the cast bars. After casting, the samples were cut to dimensions $(19 \times 10 \mathrm{~mm})$ for the cathodic protection test; the samples of dimension $(19 \times 10 \mathrm{~mm})$ were polished, degreased in acetone, dried, weighed and stored in a dessicator. The samples initial weight were taken using weighing machine (mettler AC $100 \mathrm{Ag} \mathrm{Ch}-8606$ to 0.0001 g accuracy). 100\% pure Al was cast as control.

Mild steel pipes (chemical composition given in Table 1) of internal and external diameter 19mm and $27 \mathrm{~mm}$ of length $60 \mathrm{~mm}$ were weighed and mechanically coupled with the aluminum alloy. Before coupling, the open circuit potential of the anodes and the steel were measured and recorded.

\section{Table 1: The chemical composition of the mild steel}

\begin{tabular}{|l|l|l|l|c|c|l|l|l|l|l|l|}
\hline Element & $\mathrm{C}$ & $\mathrm{Si}$ & $\mathrm{Mn}$ & $\mathrm{P}$ & $\mathrm{S}$ & $\mathrm{Cr}$ & $\mathrm{Mo}$ & $\mathrm{Ni}$ & $\mathrm{Sn}$ & $\mathrm{Cu}$ & $\mathrm{V}$ \\
\hline Percent & 0.13 & 0.15 & 0.47 & 0.043 & 0.006 & 0.01 & 0.01 & 0.01 & 0.001 & 0.03 & 0.002 \\
\hline
\end{tabular}

After the samples were coupled with the mild steel, they were immersed in natural seawater. Weight loss, polarized potential and the current required were then determined after every week for a period of 8 weeks.

After the test samples were immersed in the natural seawater, a platinum reference electrode (SHE) was immersed in the solution, the electrode and the sample were connected to a digital multimeter, which was used to measure the polarized potential with respect to standard platinum 
reference electrode (SHE). The arrangement for the measurement of the potential is given in Figure 1.

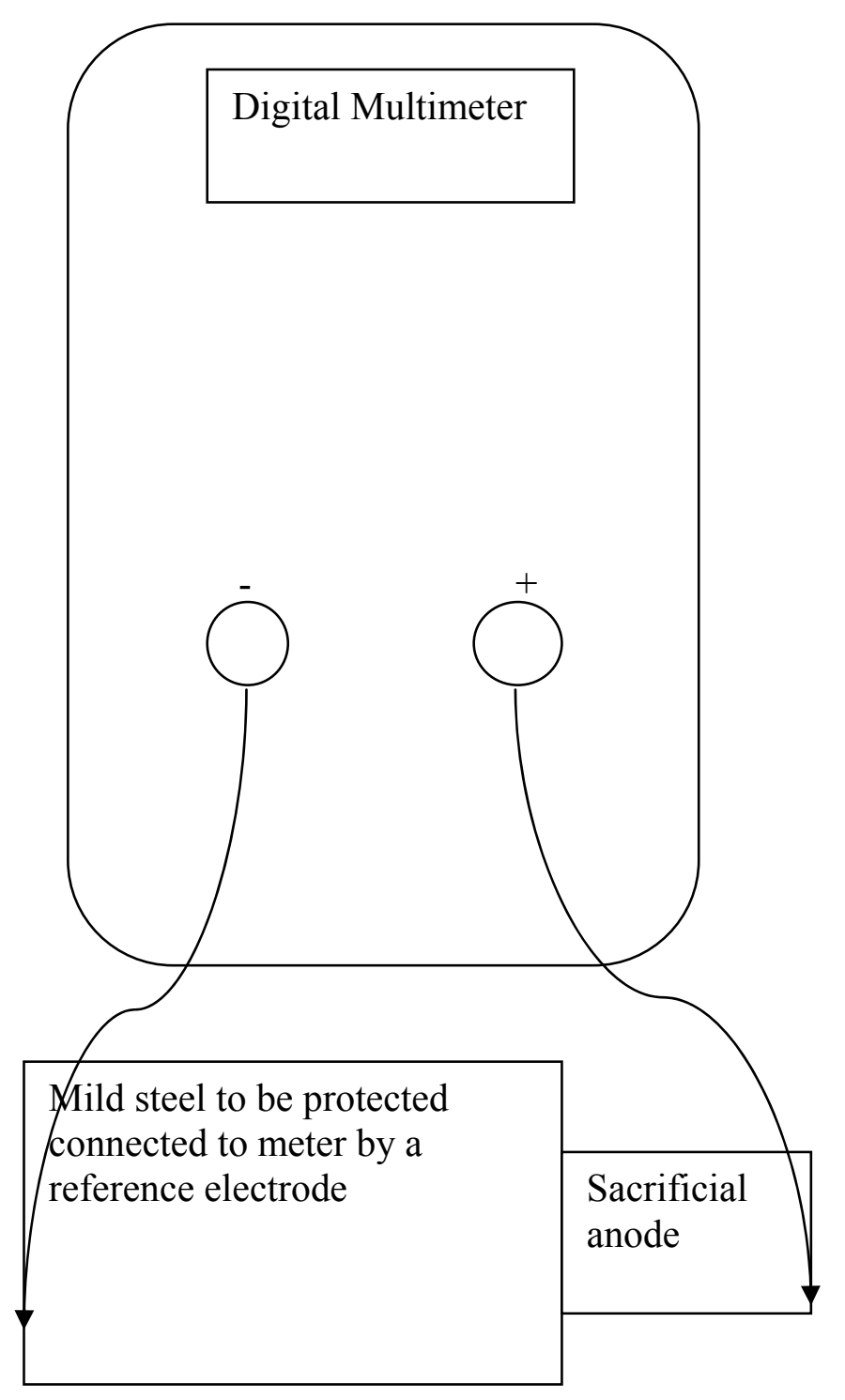

Figure 1: Arrangement for the measurement of potential and current

Also the current supplied by sacrificial anode the was measured (Tabulated in Table 2) using the same digital multimeter. The corrosion products formed on the surface were removed by scrubbing under running tap water using a fine rubber bung, after swabbing their surfaces with cotton wool soaked in ethanol, the specimens were dried and then re-weighed. 


\subsection{Determination of Chemical Composition of Seawater}

The chemical composition of the seawater used was determined using Double-Beam Digital Atomic Absorption Spectrophotometer AAS (model AA-650). Also, the pH was determined using $\mathrm{pH}$ meter (model pHS-25).

\subsection{Determination of Current Carrying capacity and Anode Efficiency}

The protection current provided by the couple was measured using digital multimeter.

The theoretical current carrying capacity value $\mathrm{CC}_{\mathrm{TH}}$ corresponding to each alloy composition was calculated using equation $1^{9}$. Tabulated in Table 2.

$$
C C_{T H}=\frac{\sum X_{i} Q_{i}}{100}
$$

Where $X_{i}$ is the mass fraction in percent of the alloying element with theoretical current carrying capacity Qi.

The anode efficiency $(\mathrm{E} \%)$ was determined using the relationship in equation $2^{10}$.

$$
E(\%)=\frac{C C_{A}}{C C_{T H}} \times 100
$$

where $\mathrm{CC}_{\mathrm{A}}, \mathrm{CC}_{\mathrm{TH}}$ are respectively the actual and theoretical current carrying capacity.

The actual current carrying capacity was calculated using equation $3^{10}$.

$$
C C_{A}=\frac{I t}{W_{i}-W_{f}} \times 100
$$

where $\mathrm{I}$ is the current in ampere, $\mathrm{t}$ is the time in hours, $\mathrm{W}_{\mathrm{i}}$ and $\mathrm{W}_{\mathrm{f}}$ are the initial and final weight in kilograms respectively.

The protection efficiency (PE) given to the steel (cathode) by the sacrificial anode was also determined for the 7 th and 8 th week by using equation 4 .

$$
P E=\frac{W_{2}}{W_{1}} \times 100
$$

Where $\mathrm{w}_{1}$ is the initial weight of the steel and $\mathrm{w}_{2}$ is the final weight of the steel.

The anode mass requirement can be calculated using equation $6^{11}$. 


$$
M=\frac{\operatorname{Im} \times t \times 8760}{\mu \times \varepsilon}
$$

Where Im is the maintenance current, $\mathrm{t}$ is the design life in years, $\mu$ is the utilisation factor normally $0.8-0.85$ for Al-based sacrificial anode ${ }^{5}, \varepsilon$ is the electrochemical capacity of anode material in $\mathrm{Ah} / \mathrm{Kg}\left(\mathrm{CC}_{\mathrm{TH}}\right.$ in Table 2$)$.

\subsection{Metallographic Analysis}

The samples for the metallographic examination before and after corrosion were ground on grades of SiC emery paper (60 - 600 grits) sizes using water as a coolant. Rough and fine polishing was done for the samples before corrosion using a 1.0 micro size aluminium polishing powder and 0.5-micron alumina powder respectively on a rotating disc of nap cloth. Fine polishing was done for the samples after corrosion. The samples were etched using $5 \mathrm{ml}$ hydrogen peroxide and $2 \mathrm{ml}$ nitric acid in $10 \mathrm{ml}$ of water, then the microstructure was recorded using an optical microscope with an in-built camera.

\section{RESULTS AND DISCUSSION}

Table 2 gives the calculated theoretical current capacity for the cast sacrificial anodes. From this table, it can be seen that the current carrying capacity of the sacrificial anodes decrease with increase in composition of alloying element (Zinc) in all the cast alloys (Al-xZn).

The open circuit potential of the sacrificial anode produced lies in the range -1.21 to $-1.44 \mathrm{~V}$ SHE and that of the steel is $-0.47 \mathrm{~V}$ SHE.

Polarized potential values for Pure aluminium-Steel and Al-xZn/Steel couples were determined (Table 2). The values obtained for pure aluminium-steel couple $(-0.62 \mathrm{~V})$ are within the recommended value (below $-0.5 \mathrm{~V}$ SHE in iron/steel pourbaix diagram) ${ }^{5}$ Standard Hydrogen Electrode. The polarized potential obtained for Al-Zn-Steel couples are within the recommended range (below $-0.5 \mathrm{~V} \mathrm{SHE}$ in iron/steel pourbaix diagram) ${ }^{5}$, with Al-6\%Zn-steel couple having the most negative potential of $-0.86 \mathrm{~V}$ SHE.

Table 3 gives the chemical composition of the seawater and the measured $\mathrm{pH}$ is 8.33 .

Figure 2 showed the variation of anodic efficiency with time for Al-xZn, sacrificial anodes in seawater. In Figure 2 it can be observed that there is an increase in anodic efficiency with time for most Al-Zn anodes, in which the increase is more pronounced in the 4th, 5th, and 6th week. Then anode efficiency decreased slightly thereafter. While the highest anodic efficiency value $(86.59 \%)$ was obtained at $6 \% \mathrm{Zn}$ after the 6 th week. The low initial efficiency could be attributed to the formation of stable oxide layer of Alumina, which initially retarded the dissolution rate of 
the metal. But as the time of exposure was increased, the stable oxide layer was broken and could not protect the metal from further dissolution. This is in line with the observation of Shibli et. al 2008. The decrease and the low efficiency value could be attributed due to re-passivation and chunk effect which is the physical detachment of metal from the bulk sacrificial anode, the missing metal is no longer useful for cathodic protection and the efficiency is lowered ${ }^{10}$.

Table 2:Composition, polarized potential, current, anode efficiency, calculated theoretical current capacity of cast Al-Zn sacrificial anodes

\begin{tabular}{|l|l|l|l|l|}
\hline Composition & $\begin{array}{l}\text { Polarized } \\
\text { Potential of the } \\
\text { Couple }\end{array}$ & $\begin{array}{l}\text { Actual } \\
\text { Current/mA }\end{array}$ & $\begin{array}{l}\text { Anode } \\
\text { Efficiency/\% }\end{array}$ & $\begin{array}{l}\text { Theoretical Current } \\
\text { Capacity/CC }\end{array}$ \\
\hline $\begin{array}{l}\mathrm{TH}(\varepsilon) \\
\text { Aluminium }\end{array}$ & -0.62 & 0.03 & 21.23 & 2981 \\
\hline Al-1\%Zn & -0.72 & 0.11 & 62.63 & 2959 \\
\hline Al-2\%Zn & -0.77 & 0.12 & 73.14 & 2938 \\
\hline Al-3\%Zn & -0.77 & 0.12 & 66.24 & 2916 \\
\hline Al-4\%Zn & -0.77 & 0.14 & 77.62 & 2895 \\
\hline Al-5\%Zn & -0.81 & 0.16 & 77.16 & 2873 \\
\hline Al-6\%Zn & -0.86 & 0.18 & 86.59 & 2851 \\
\hline Al-7\%Zn & -0.83 & 0.17 & 77.62 & 2851 \\
\hline Al-8\%Zn & -0.81 & 0.17 & 69.38 & 2808 \\
\hline
\end{tabular}

Table 3 Chemical composition of the seawater

\begin{tabular}{|l|l|l|l|l|l|l|l|l|l|l|l|l|}
\hline Description & $\mathrm{K}$ & $\mathrm{Na}$ & $\mathrm{Ca}$ & $\mathrm{Mg}$ & $\mathrm{Cu}$ & $\mathrm{Zn}$ & $\mathrm{Mn}$ & $\mathrm{Fe}$ & $\mathrm{Cr}$ & $\mathrm{Co}$ & $\mathrm{Ni}$ & $\mathrm{P}$ \\
\hline Concentration/ppm & 3.90 & 5.66 & 2.00 & 0.350 & 0.000 & 0.225 & 0.250 & 0.750 & 0.000 & 0.550 & 1.150 & 0.500 \\
\hline
\end{tabular}




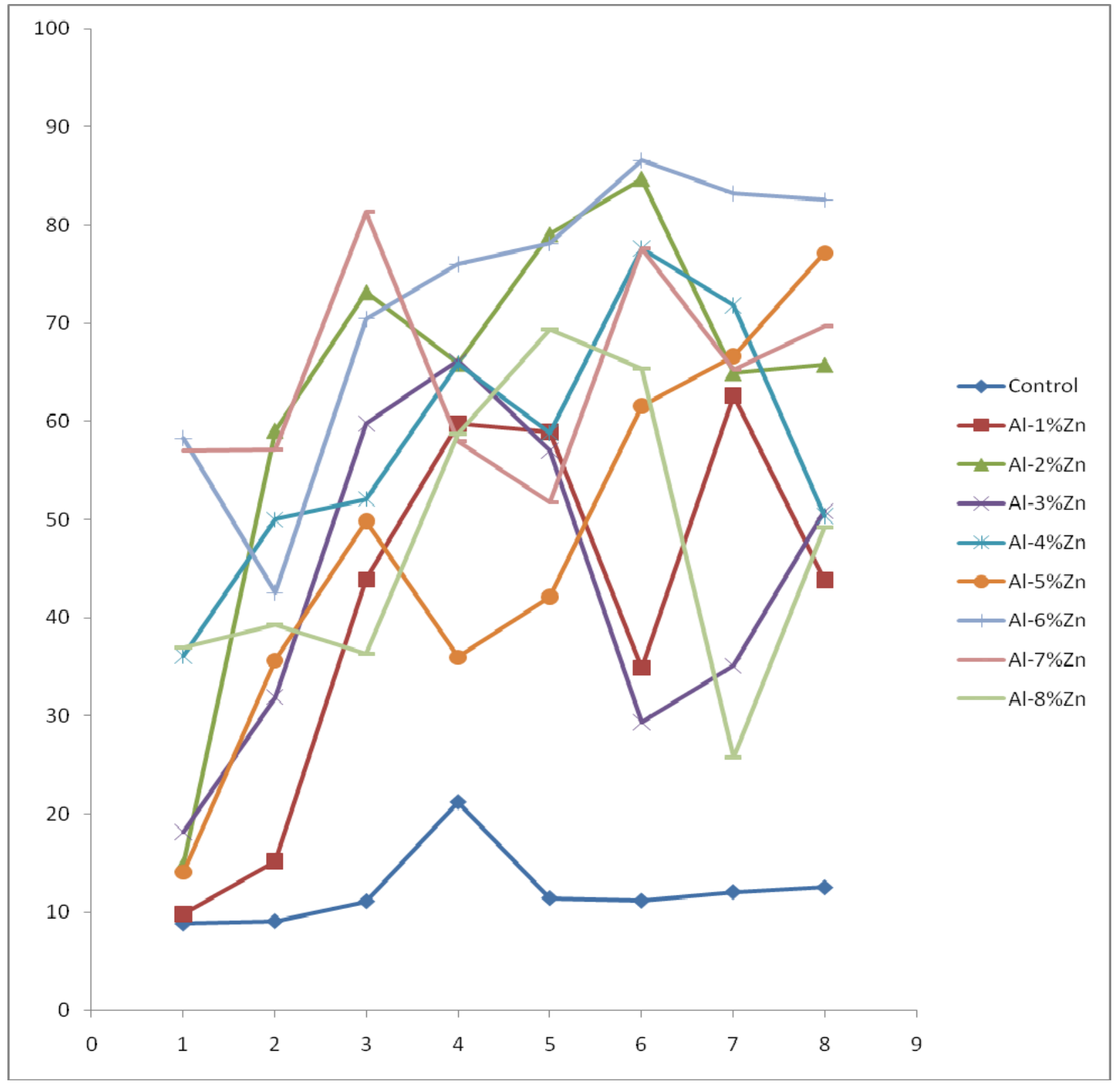

Fig. 2: A plot of anodic efficiency with time of Al-Zn alloys in seawater

Figure 3 is the variation of peak anodic efficiency with $\% \mathrm{Zn}$ in aluminium sacrificial anode. The Figure shows an increase in anode efficiency with increase in $\% \mathrm{Zn}$ addition in the sacrificial anode. The highest anodic efficiency of $86.59 \%$ is attained at $6 \% \mathrm{Zn}$ addition. 


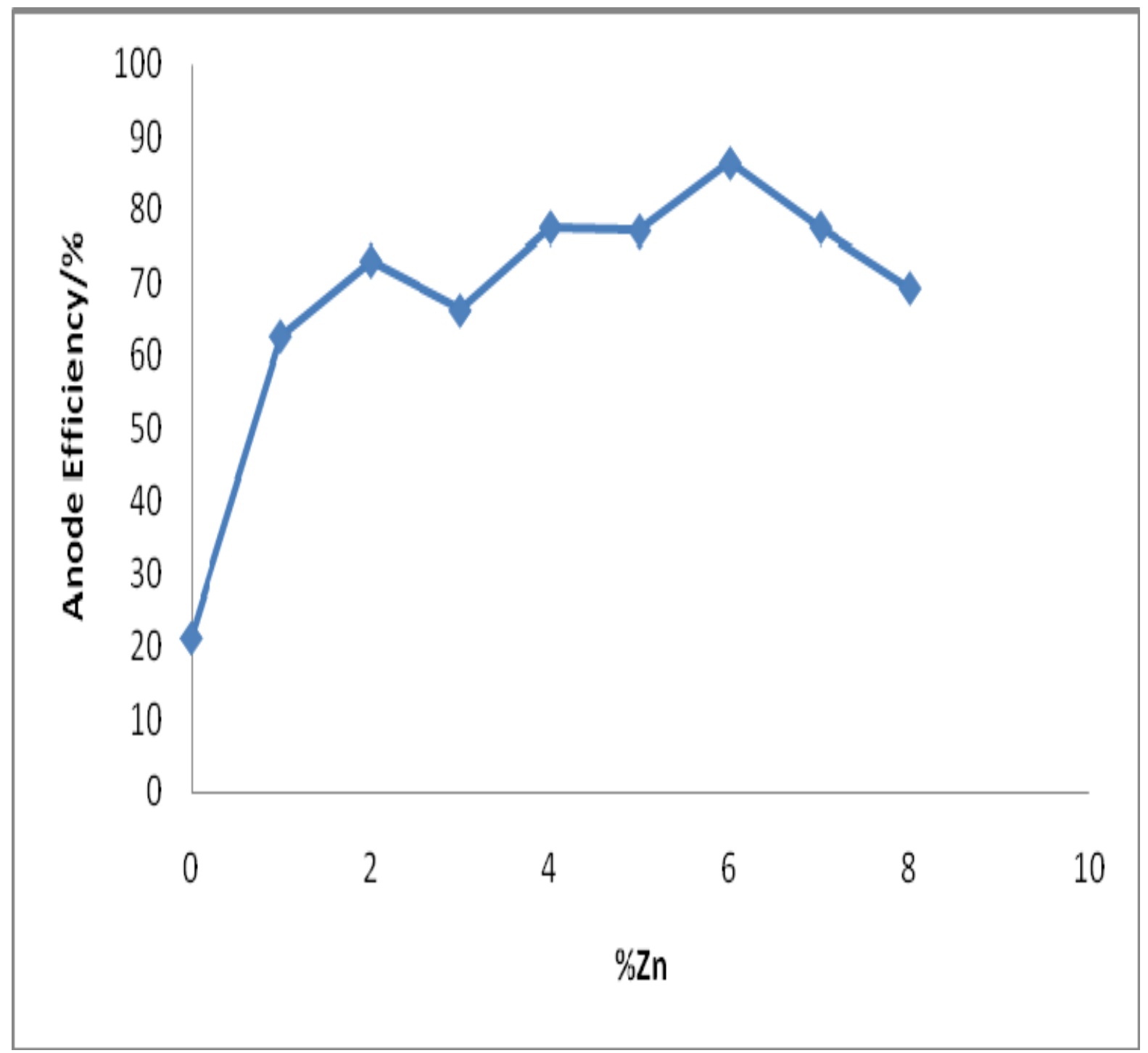

Fig 3: Variation of Anode Efficiency with \%Zinc

The protection efficiency given to the steel by the aluminium sacrificial anode(Table 4) was calculated. Pure aluminium has the least protection efficiency of $93.13 \%$ and $92.84 \%$ at the 7 th and 8th week respectively. For Al-Zn sacrificial anodes, Al-6\%Zn has protection efficiency of $99.26 \%$ and $99.13 \%$ at the 7 th and 8 th week respectively. 
Table 4: Protection efficiency of the Al-Zn alloys

\begin{tabular}{|l|l|l|l|l|l|l|l|l|l|}
\hline & Control & $1 \%$ Zn & $2 \%$ Zn & $3 \%$ Zn & $4 \%$ Zn & $5 \%$ Zn & $6 \%$ Zn & $7 \%$ Zn & $8 \%$ Zn \\
\hline 7th week & 93.13 & 94.89 & 95.04 & 95.99 & 97.20 & 95.13 & 99.26 & 98.39 & 97.13 \\
\hline 8th week & 93.76 & 95.72 & 95.28 & 96.35 & 97.49 & 95.35 & 99.13 & 97.62 & 97.29 \\
\hline
\end{tabular}

The low initial efficiency of the Al-Zn sacrificial anode could be attributed to the formation of stable oxide layer of alumina, which retarded the dissolution rate of the metal during its exposure in saline medium. But as the time of exposure was increased, the stable oxide layer was broken and could not protect the metal from further dissolution. The results shown above indicated that the second phase particle formed was responsible for depassivating aluminium. The second phase particles formed in Al-Zn alloys is $\beta$-phase shown in Figures 4-15. This second phase particles led to breakdown of passive film of $\mathrm{Al}_{2} \mathrm{O}_{3}$ formed on the aluminium surface and result in the increase in anode efficiency and reduced the dissolution resistance of aluminium sacrificial anode $^{11}$.

The polarized potential obtained for Al-Zn sacrificial anode lies in the range required to polarized the potential of steel during cathodic protection that is below $-0.5 \mathrm{~V}$ with $\mathrm{Al}-6 \% \mathrm{Zn}$ having the most negative polarized potential ${ }^{5}$.

The protection efficiency results obtained have shown that pure aluminium has the least protection efficiency. This illustrated that the aluminium anode could not give steel enough protection, as a result the steel is corroding. For Al-Zn sacrificial anodes, Al-6\% $\mathrm{Zn}$ has the highest protection efficiency.

The anode mass required can be calculated by using equation 5 from the values of current $\mathrm{i}$ (Table 2), utilisation factor $\mu$, and electrochemical capacity of the anode material $\varepsilon\left(\mathrm{CC}_{\mathrm{TH}}\right)$ in $\mathrm{Ah} / \mathrm{Kg}$ (Table 1$)$ at any given time ( $\mathrm{t}$ in years). 


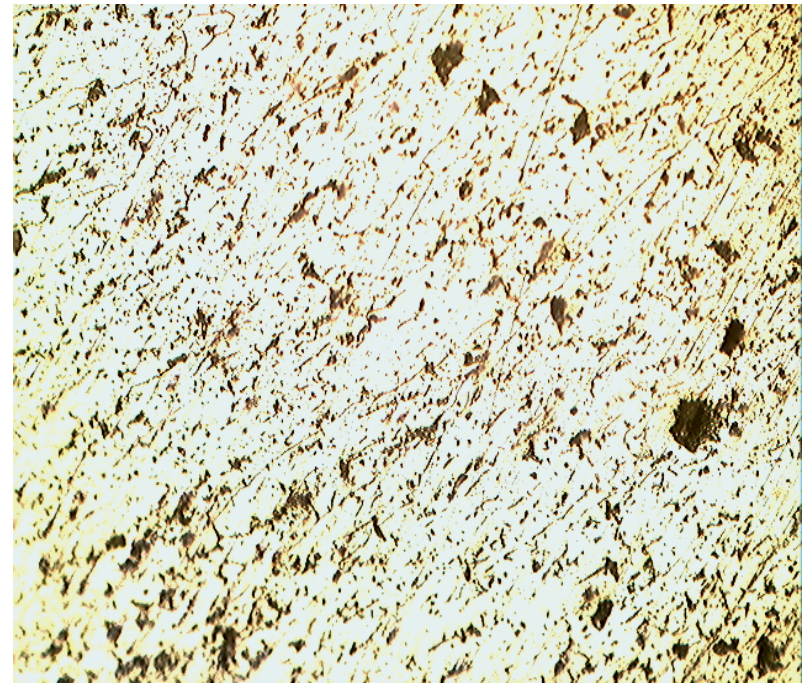

Fig 4: Micrograph of as-cast aluminium showing $\quad \alpha$-solid-solution (whitematrix).200X

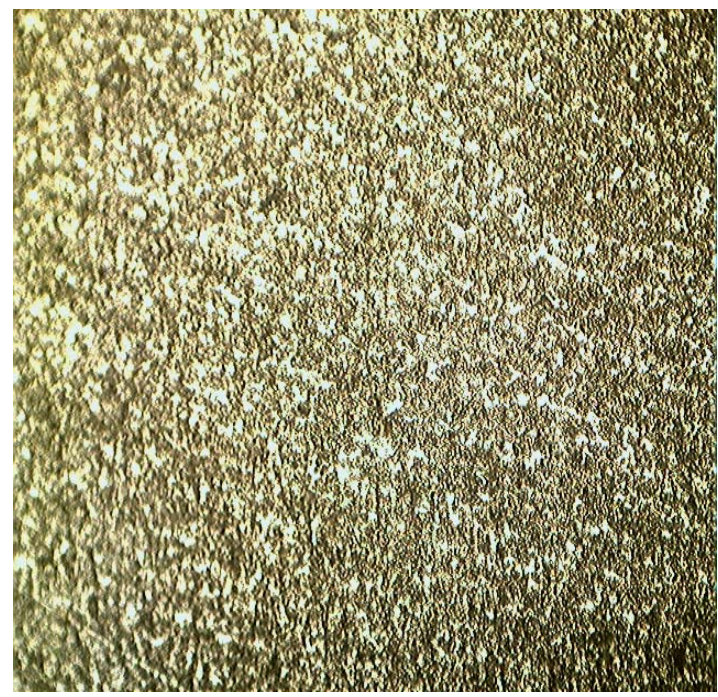

Fig 6: Micrograph of as-cast Al-1\%Zn showing $\alpha$-Al matrix(white) and $\beta$-Zn phase dark. 200X

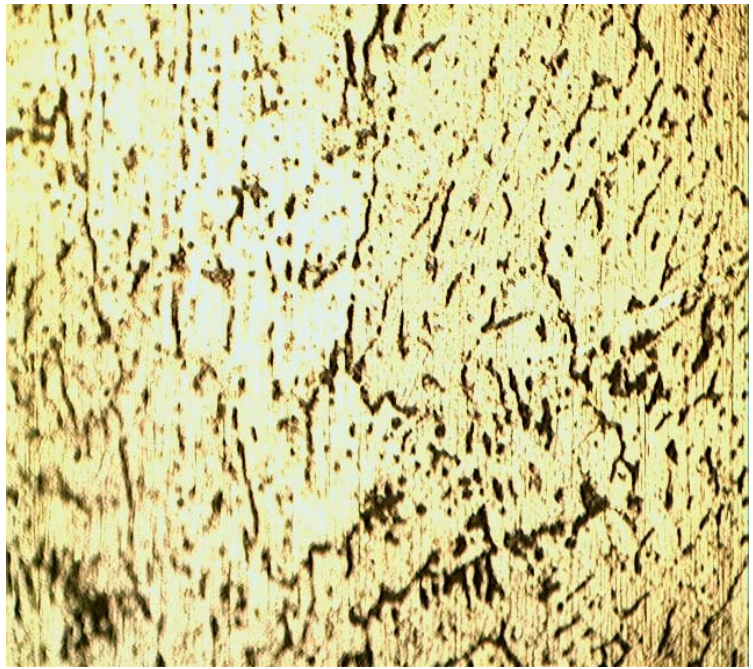

Fig 5: Micrograph of aluminium/steel couple after immrsion in seawater for 8 weeks.200X

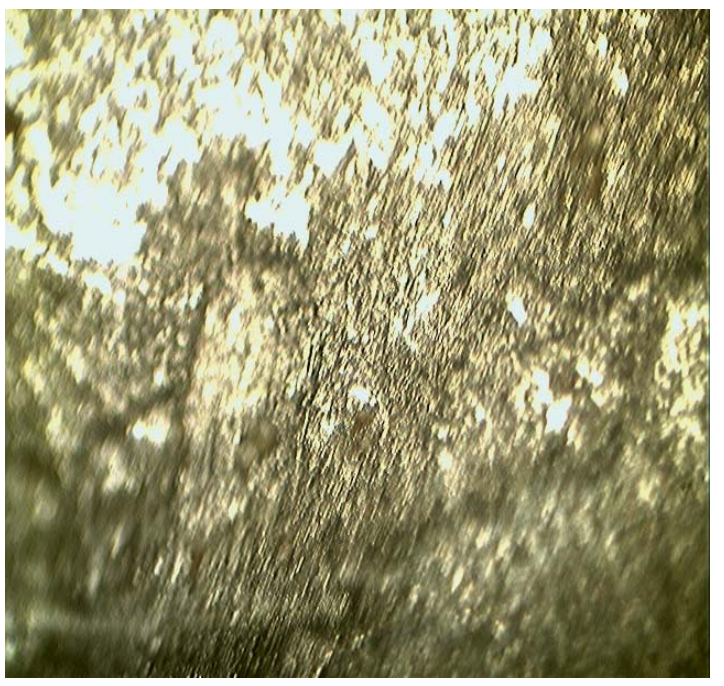

Fig 7: Micrograph of $\mathrm{Al}-1 \% \mathrm{Zn}$ after immersion in seawater for 8 weeks showing dark regions of corrosion product. 200X 


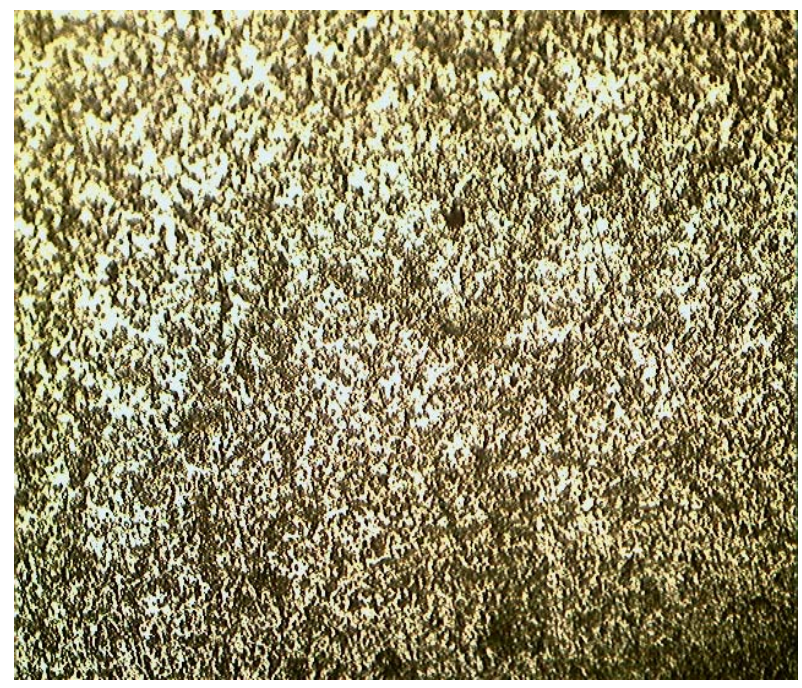

Fig 8: Micrograph of as-cast $\mathrm{Al}-2 \% \mathrm{Zn}$ showing $\alpha$-Al matrix(white) and $\beta-Z n$ phase dark. 200X

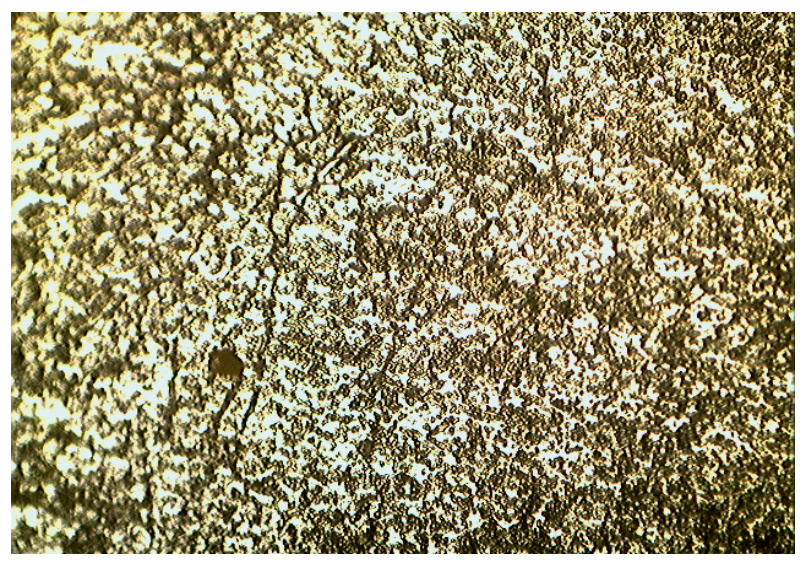

Fig 10: Micrograph of as-cast Al-4\%Zn showing $\alpha$-Al matrix(white) and $\beta-Z n$ phase dark. 200X

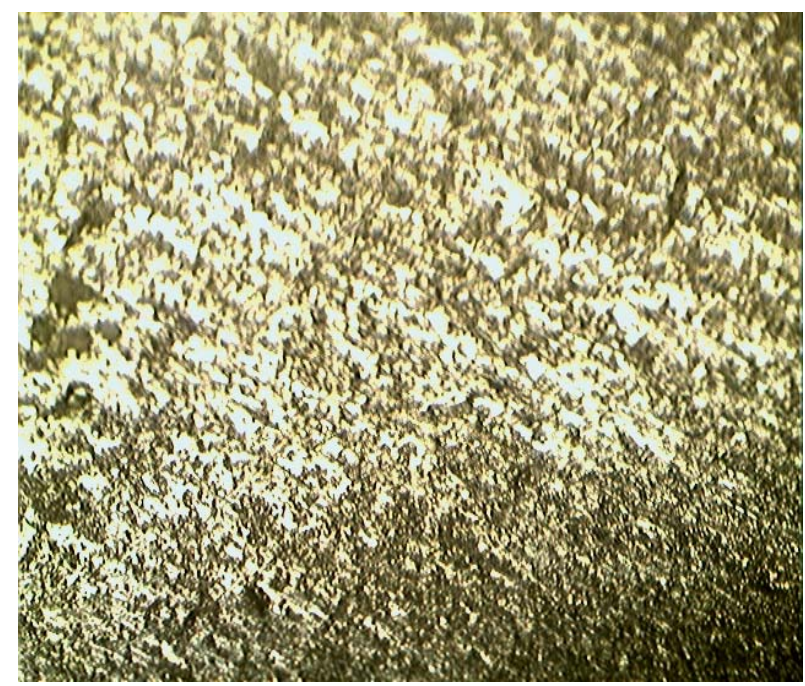

Fig 9: Micrograph of Al-2\%Zn after immersion in seawater for 8 weeks showing dark regions of corrosion product. 200X

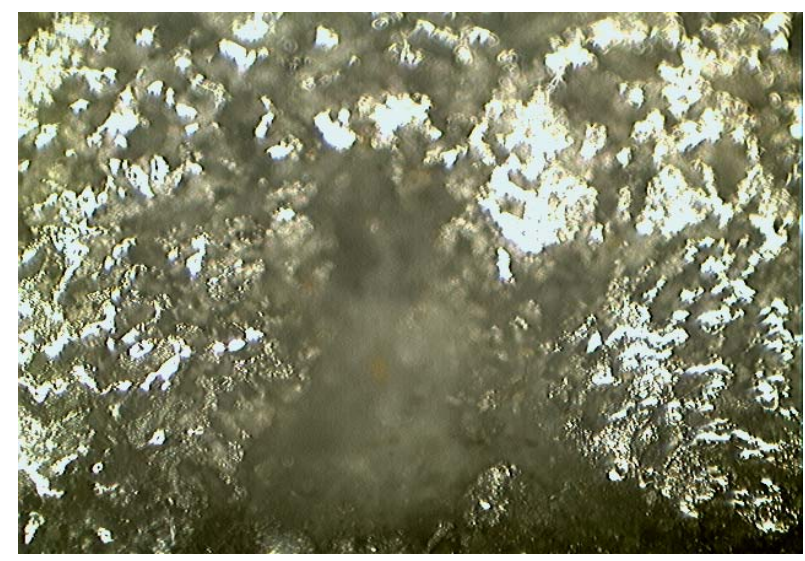

Fig 11: Micrograph of Al-4\%Zn after immersion in seawater for 8 weeks showing dark regions of corrosion product. 200X 


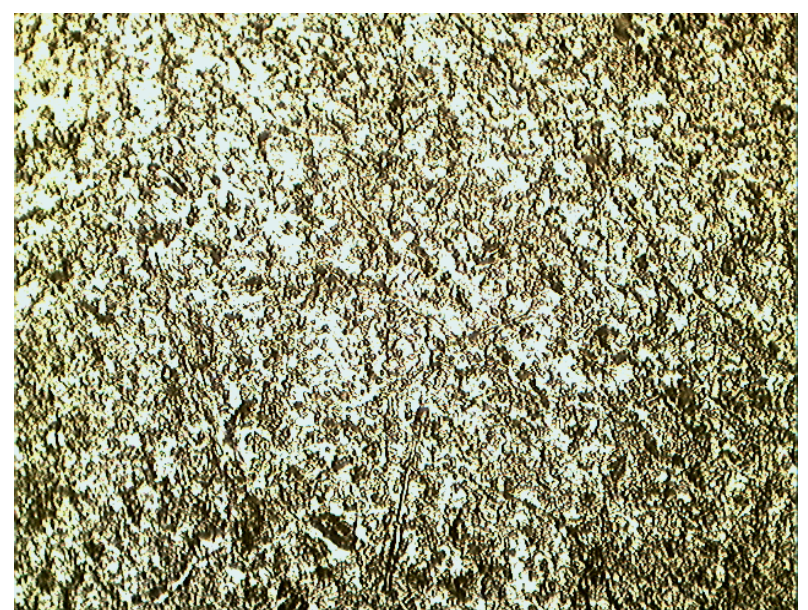

Fig 12: Micrograph of as-cast Al-6\%Zn showing $\alpha$-Al matrix(white) and $\beta-Z n$ phase dark. 200X

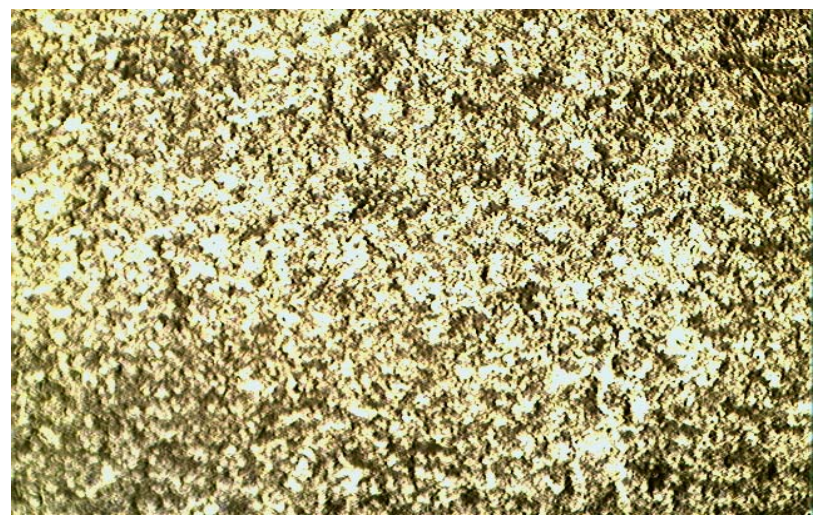

Fig 14: Micrograph of as-cast $\mathrm{Al}-8 \% \mathrm{Zn}$ showing $\alpha$-Al matrix(white) and $\beta$-Zn phase dark. 200X

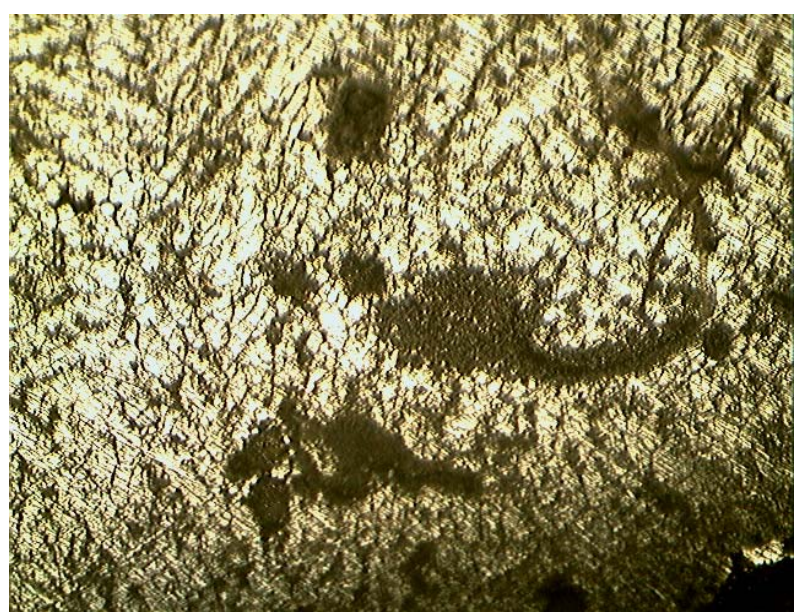

Fig 13: Micrograph of $\mathrm{Al}-6 \% \mathrm{Zn}$ after immersion in seawater for 8 weeks showing dark regions of corrosion product. $200 \mathrm{X}$

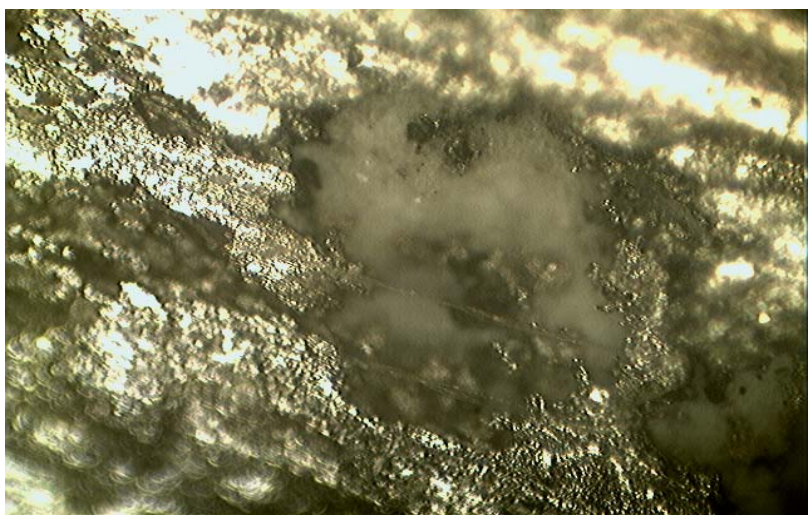

Fig 15: Micrograph of $\mathrm{Al}-8 \% \mathrm{Zn}$ after immersion in seawater for 8 weeks showing dark regions of corrosion product. 200X 


\section{CONCLUSION}

Based on this research it can be concluded that alloying elements decrease the value of theoretical current carrying capacity of aluminium and anode efficiency of the Al-Zn sacrificial anode is dependent both on time and composition. The polarized potential obtained for the couples lies in the immunity region of steel( $\leq-0.5$ V SHE). Presence of second phase particle $\beta$-phase (as shown in the photomicrographs) probably aid in the breakdown of alumina passive film resulting in the dissolution of more of the Aluminium sacrificial anode, hence increasing the quantity of charge release for cathodic protection. The anode mass requirement can be calculated using $\varepsilon\left(\mathrm{CC}_{\mathrm{TH}}\right)$ in Table 2 at any given time( $\mathrm{t}$ in years).

\section{REFERENCES}

1. Baxter, D. and Britton J. (2006). Offshore Cathodic Protection 101, 10851 Train Court, Houston, USA.

2. Talbot, D. and Talbot, J. (1997), Corrosion Science and Technology; CRC Press, LLC, London.

3. Unified Facilities Criteria (2005), Cathodic Protection, Department of Defence, United States of America.

4. Evans, U.R. (1963); An Introduction to Metallic Corrosion, London Edward Arnold (Publishers) Ltd.

5. Corrosion - Doctors.org/Corrosion-Thermodynamics/Potential-pH-diagram-water, htm, (2009).

6. Genesca, J. and Juareg, J. (2007), Development and Testing of Galvanic Anodes for Cathodic Protection, Contributions to Science 1 (3): 331 - 334, Catalan, Barcelona.

7. Gurappa, J. Corrosion Prevention and Control 44, Pp. 69, India.

8. Reboul, M.C., Gimenes, P.H., Rameau, J.J., (1984), Article on Corrosion 40, Pp.366.

9. Cathodic Protection Handbook.1997), Theory and Practice of Electrochemical Protection Processes.

10. Di Gabriele, F. and Canterbury, J. D. (2003), Corrosion Behaviour of Magnesium Sacrificial Anodes in tap water; Corrosion protection centre, Umist, P O. Box 88, Manchester, M60 1QD, UL.

11. Metals Handbooks (1990), Properties and Selection; Nonferrous Alloys and Special Purpose Material, American Society of Metals (ASM) Vol. 2.

12. Shibli, S.M.A., Archana, S.R. and Muhammed, P.A. (2008); Development of Nano Cerium Oxide Incorporated Aluminium Alloy Sacrificial Anode for Marine Applications, Department of Chemistry, University of Karalla, India.

13. Meillier, A., A Review of Galvanic Anode Cathodic Protection Design Procedure, Corrosion Control Services Limited,Stafford Park, Telford, U.K. 